\title{
Perancangan Kartu Tarot Astadewa Berdasarkan Cerita dan Karakter Perwayangan Mahabharata
}

\author{
Andya Dewakinnara dan R. Eka Rizkiantono \\ Departemen Desain Produk, Fakultas Arsitektur, Desain, dan Perancangan, \\ Institut Teknologi Sepuluh Nopember (ITS) \\ e-mail: ekaindian007@gmail.com
}

\begin{abstract}
Abstrak-Tarot Wayang yang diciptakan oleh Ibu Ani Setyaningsih, adalah Kartu Tarot pertama yang pernah di publikasikan di Indonesia. Tetapi, keberada-an kartu ini semakin sedikit, karena Gramedia memutuskan untuk tidak mencetak kembali kartu Tarot Wayang ini. Dikarenakan itulah, Penulis me-mutuskan untuk meneruskan kembali jejak Ibu Ani dan terus melestarikan budaya Wayang yang dipenuhi oleh simbolisme. Dengan melakukan beberapa metode penelitian, wawancara, observasi, studi literatur hingga Focus Group Discussion, Penulis mengumpulkan banyak data untuk melakukan perancangan sebuah dek tarot yang berbeda dari Standar Universal Waite Rider. Dek tersebut lebih mengarah kepada simbolisme per-wayangan Jawa dan menggunakan ilustrasi yang lebih detail daripada Tarot Wayang Ibu Ani. Wujud akhir dari perancangan tersebut adalah terciptanya sebuah Tarot bernama Astadewa dengan media ilustrasi digital yang dapat mempresentasikan budaya perwayangan Jawa, menggunakan simbol-simbol cerita dan karakter Mahabarata. Diharapkan, kartu ini dapat menjadi media pelestarian wayang, yang dapat digunakan oleh orang dalam negeri maupun luar negeri.
\end{abstract}

Kata Kunci-Tarot, Simbolisme, Wayang, Ilustrasi, Mahabharata, Kartu.

\section{PENDAHULUAN}

$\mathrm{W}$ AYANG memiliki persamaan dalam simbolisme seperti Tarot. Keduanya memiliki arti-arti tersembunyi. Wayang dalam boneka dan propertinya, dan tarot dipresentasikan melalui gambar. Dalam makna, wayang dan tarot memiliki kesamaan cerita yang ingin disampaikan, yaitu perjalanan manusia dalam pencarian dan pengembangan jati diri. Perbedaannya wayang yang memiliki pakem tetap, sedangkan menurut interview dengan Barbara Moore seorang pakar Tarot sejak 1990 dari Inggris pada tanggal 3 Maret 2016, bahwa tarot adalah salah satu elemen budaya yang fleksibel. Tarot juga telah ada sejak abad ke-15 dan telah berubah sesuai zaman, sesuai era, sesuai keadaan geografis dan kebudayaan, merefleksikan keyakinan manusia. Sehingga, Tarot menjadi salah satu elemen fleksibel, sehingga mudah dirasuki budaya, adat, dan simbolisme yang berbeda sesuai dengan perjalanan sang pencipta jenis tarot. Penggunaan Tarot sebagai media peles-tarian juga dapat memiliki pengaruh terhadap pengenalan Wayang ke masyarakat asing.

Lalu melalui wawancara dengan Guruh Nusantara, sebagai wakil ketua Komunitas Fullmoon, pada tanggal 5 Desember
2014, bahwa adanya keterkaitan dibalik cerita dasyhat Mahabarata dan simbol-simbol di dalam Tarot. Telah dijelaskan bahwa Mahabarata mencakup segala aspek dalam kehidupan manusia, dan Tarot adalah miniatur dari kehidupan itu sendiri. Sehingga penulis menjadikan Mahabharata sebagai tema dari Tarot Astadewa ini.

Pengaplikasian elemen wayang ke dalam kartu Tarot telah dilakukan sebelumnya oleh Ibu Ani Sekarningsih yang diterbitkan oleh Gramedia beberapa tahun lalu. Kedua kartu Tarot ini telah terkenal dikalangan para pemain tarot Indonesia dan beberapa dari pemain luar negeri. Tarot Wayang milik Ibu Ani menjualnya hanya dapat ditemui melalui internet karena buku dan kartunya sudah tidak diproduksi kembali di toko buku. Sehingga Tarot ini sudah semakin sulit di temukan dan akan habis pada akhirnya.

\section{A. Identifikasi Masalah}

1) Tarot Astadewa membutuhkan ilustrasi Tarot berbasis wayang yang dapat mempresentasikan budaya perwayangan Indonesia.

2) Tidak banyaknya media wawasan tentang sim-bolisme Perwayangan Jawa.

3) Diperlukannya Tarot berbasis Wayang yang berbeda dari milik Ibu Ani Setyaningsih, yang kali ini memiliki visual yang dapat menampung sim-bolisme Perwayangan Jawa. Hal ini juga untuk meneruskan Tarot Wayang yang sudah tidak di-produksi kembali.

\section{B. Rumusan Masalah}

Bagaimana cara mengaplikasikan simbolisme antara Perwayangan Jawa dan Tarot Waite Rider ke dalam Kartu Tarot Astadewa sehingga dapat mempresen-tasian budaya Perwayangan di dalam-nya?

\section{Batasan Masalah}

1) Ilustrasi meliputi 78 Kartu Tarot, 22 Arkana Mayor dan 56 Arkana Minor. Tetapi pembahasan tentang perubahan visual di dalam laporan ini hanya terbatasi 22 Arkana Mayor saja. Hal ini dikarenakan ketidak-sanggupan penulis untuk menuliskan kompleksnya Arcana Minor dan keterbatasan waktu yang dimiliki penulis.

2) Kartu Tarot Astadewa akan menggunakan Tarot Rider Waite acuan membuat Kartu. Karena Tarot Rider Waite adalah acuan paling populer yang digunakan hampir di seluruh Tarot. Mudah dimengerti dan dipelajari. 
3) Perancangan hanya mencakup cerita dan karakter-karakter perwayangan di dalam kisah Mahabarata.

4) Perancangan ilustrasi Tarot Astadewa mengguna-kan simbolisme dari Keraton Yogyakarta, wayang purwa dan wayang orang sebagai dasar mendesain setiap kartunya.

D. Tujuan

1) Penelitian ini diharapkan tidak hanya dapat menggambarkan Tarot Astadewa yang mem-presentasikan budaya Perwayangan.

2) Penelitian ini diharapkan dapat memperkenalkan simbolsimbol di dalam Perwayangan yang belum diketahui pembaca dan menjadikannya pengetahuan baru.

\section{TINJAUAN PUSTAKA}

\section{A. Landasan Teori}

1) Simbolisme dalam Tarot

Penjelasan mengenai manusia dan simbol yang dibahas berdasarkan prespektif dari Psikoanalitik Carl Gustav Jung, bahwa Tarot bukanlah klenik, komunikasi dengan roh jahat, tahayul, ramalan, atau berbagai anggapan buruk lain. Tarot hanyalah salah satu medium untuk menemukan alternatif pemecahan masalah-masalah kehidupan yang dialami oleh manusia [1].

2) Kesadaran dan Ketidaksadaran Kolektif

Bagi Jung alam bawah sadar bukan merupakan tempat sampah bagi hal-hal yang ditekan, tetapi merupakan sahabat, penasihat, penghantar dan petunjuk bagi manusia. Bahasa khas alam bawah sadar adalah simbolis, salah satunya adalah mimpi dan myth. Jung menamai bahasa simbolis yang berulang ini dengan istilah Arketipe [1].

3) Arketipe

Arketipe menurut Jung berasal dari pen-caharian yang berulang-ulang, misalnya myth dan dongeng-dongeng dari dunia sastra yang mengandung pola-pola dasar tertentu, yang muncul dimana-mana. Manusia menemukan pola dasar yang sama ini dalam fantasi-fantasi, mimpi-mimpi dan khayalan dari individu.

4) Arkana Mayor

Dua puluh dua rupa kartu Arkana Mayor menggambarkan tingkat-tingkat arketipe kehidupan. Kartu Arkana Mayor citranya sangat kuat, karena kartu-kartu tersebut menggambaran persilangan kehidupan penanyadan merefleksikan proses psikologis yang penting dan potensipotensi yang belum digunakan-nya [2].

5) Tokoh dan Cerita Perwayangan Mahabharata

Mahabharata mengisahkan tentang konflik para Pandawa Lima dengan saudara sepupu mereka yang berjumlah seratus orang, bernama Kurawa. Mereka memperebutkan hak pemerintahan negara Hastina-pura. Tokoh-tokohnya meliputi kelima Pandawa, Bima, Arjuna, Yudhistira, Nakula, Sadewa. Lalu Kurawa yaitu Duryudana, Dusasana. Juga para tokoh pendukung seperti Kresna, Bhisma, juga para Punakawan [3].

\section{B. Studi Eksisting}

1) Tarot Nusantara

Tarot ini menggunakan gambar flat design, dan menggunakan kebudayaan Nusantara. Hisyam A. Fachri menuliskan di bukunya, bahwa Tarot Nusan-tara menggunakan tipologi dari Carl Gustav Jung [4].

2) Tarot Wayang

Kartu Tarot Wayang, adalah kartu Tarot yang diciptakan oleh Ani Sekarningsih. Cetakan pertama diterbitkan oleh Grasindo. Kartu ini adalah kartu Tarot pertama yang mempresentasikan Perwayangan di Indonesia, khususnya Jawa [5].

3) Tarot Shadowscapes

Tarot Shadowscapes menggunakan sentuhan cat air digabungkan dengan fantasi, fairytale, dongeng dan folklor. Dengan fitur introduksi dari pemain tarot profesional Barbara Moore untuk pemain pemula, instruksi yang ringan, dan sebaran-sebaran ringkas [6].

4) Tarot Dragon Age

Penciptanya adalah Nick Thornborrow sebagai salah satu konsep artist dari Bioware. Menggunakan tradisi Rider Waite, beberapa simbol sangat unik, karakter dan sebagian dari kartunya hanya bisa dimengerti oleh pemain game dari Dragon Age Inquisition.

\section{METODE PENELITIAN}

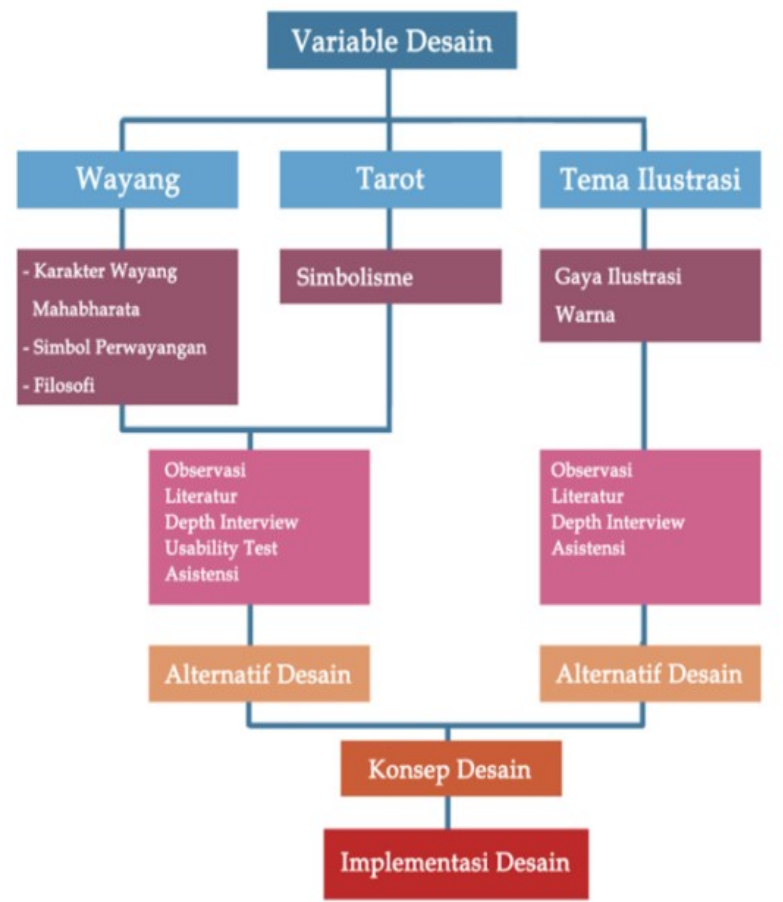

Gambar 1. Skema metode penelitian.

\section{ANALISA DATA}

A. Depth Interview

1) Barbara Moore

2) Guruh Nusantara

3) Eria Andi Anggoro

4) Dalang Ki Cermo Soetrdjo

B. Observasi

1) Sanggar Wayang Orang Sriwedari

2) Kraton Yogyakarta 
C. Focus Group Discussion

1) Facebook Komunitas Tarot Jakarta

2) Facebook Komunitas Tarot Internasional (Tarot Nerds)

D. Studi Literatur

1) Wayang Wong, Soedarsono, 1984.

2) Lordly Shades : Wayang Purwa Indonesia, Pandam Guritno dan Molly Bondan, 1984.

3) Batik : Design, Style and History, Fiona Kerlogue, 2004.

4) Laporan Penelitian Mengungkapkan Nilai Kefilsafatan yang Terkandung Dalam Kayon Perwayangan, Suyadi Mulyono, 1984.

5) Motif Batik, Chandra Irawan Sukamto, 1986.

E. Studi Komparator

1) Tarot Shadowscapes

2) Tarot Wayang

F. Hasil Analisa

1) Analisa Depth Interview Tarot

2) Analisa Depth Interview Wayang

3) Analisa Kompetitor dan Komparator

G. Hasil Analisa Impementasi Desain

1) The Fool - Bagong

2) The Magician - Semar

3) The High Priestess - Dewi Saraswati

4) The Empress - Dewi Gandari

5) The Emperor - Duryudana

6) The Hierophant - Begawan Abiyasa

7) The Lovers - Wisnu dan Laksmi

8) The Chariot - Kereta Kresna

9) The Strength - Bima

10) The Hermit - Yudhistira

11) The Wheel of Fortune - Gunungan

12) Justice - Batara Wisnu

13) The Hanged Man - Bisma

14) The Death - Batara Yamadipati

15) The Temperance $-\mathrm{x}$

16) The Devil - Sengkuni

17) The Destroyer - Batari Kali/Durga

18) The Star - $\mathrm{x}$

19) The Moon - Dewi Gangga

20) The Sun - Garuda

21) Judgement - Bisma dan Amba

22) The World - Sang Dewaruci

\section{KONSEP DESAIN}

Setelah melakukan proses penelitian melalui Depth Interview bersama pakar-pakar pemain Tarot dan Observasi pada kartu luar dan dalam negeri, maka didapatkanlah konsep perancangan untuk 78 Kartu Tarot Astadewa yang menggunakan acuan dari Taro Rider Waite.

\section{A. Elemen dalam Tarot dan Wayang}

1) Simbolisme

Persamaan dari Tarot dan Perwayangan sim-bolisme yang akan dipergunakan. Cara penyam-paian dan penggambaran simbolisme yang benar. Intepretasi dari setiap kartu tetap sama namun menggunakan simbol yang berbeda.
2) Karakter dan Arketipe

Karakterisasi adalah elemen yang sangat penting dalam Tarot Astadewa. Karena arketipe-arketipe yang telah disebutkan oleh Jung, telah direpresentasikan oleh banyak karakter dalam perwayangan. Filosofi di dalam pakaian, senjata, dan kepribadian adalah hal yang sangat perlu di perhatikan.

\section{3) Cerita}

Tidak hanya kepribadian, cerita Mahabharara juga menentukan dimana karakter-karakter akan di tempatkan di salah satu kartu Arkana Mayor.

\section{B. Warna}

Referensi warna yang di ambil adalah colour palet milik Dragon Age: Inquisition Concept's Art. Dimana Matthew Gould (2014) sebagai Art Director dari Dragon Age sangat mencintai dan ingin menciptakan kesan yang dibawa oleh Hans Holbein, seorang pelukis dari abad ke-16. [1]
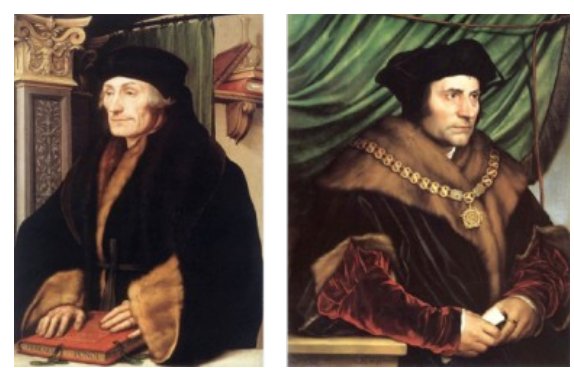

Gambar 3. Thomas (kanan) dan Erasmus of Rotterdam (kiri)

(Sumber: wikipedia.com)

Pemilihan tone warna yang didominasi dengan warna pekat dan pastel dalam satu ilustrasi. Menandakan kedalaman dari perspektif yang sangat kontras, dengan cara menggunakan warna pekat pada gambar yang berjarak dekat dengan mata.
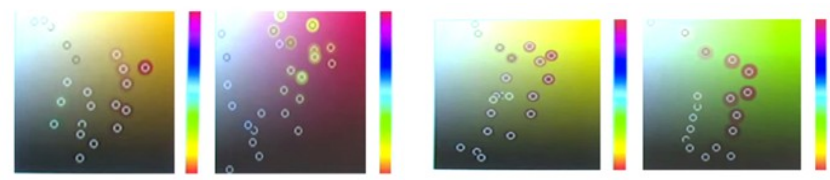

Gambar 4. Dragon Age Color Pallete. (Sumber: www.youtube.com)

\section{Karakter Dalam Perwayangan}

1) Atribut
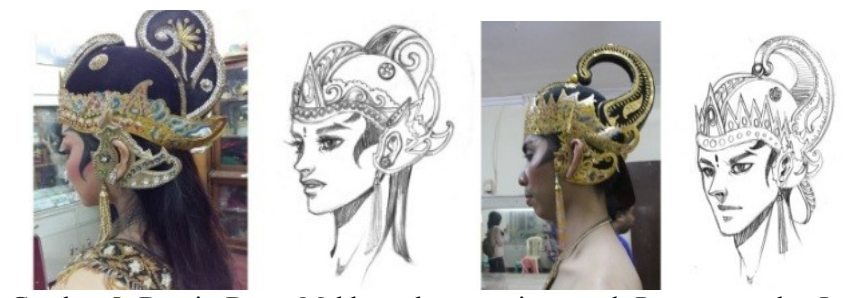

Gambar 5. Desain Dasar Mahkota dan sumping untuk Perempuan dan Lakilaki. 

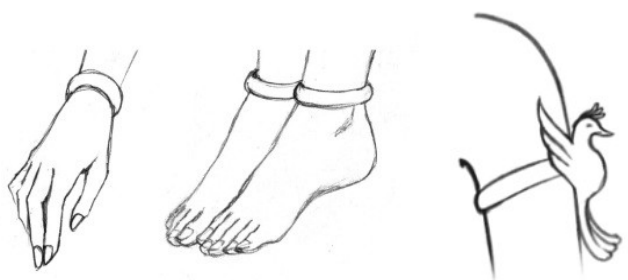

Gambar 6. Gelang kaki, gelang tangan, kelat bahu.

2) Kostum

Pada dasarnya, kostum yang digunakan wayang orang berupa celana pendek selutut, ditutupi kain batik yang digunakan seperti sarung atau di Jawa dikenal sebagai istilah dodot. Ditambahi oleh selendang dan aksesoris emas di depannya. Namun beberapa tokoh yang biasanya lebih tua atau karakter dewa, seperti Resi Durna dan Batara Guru, malah menggunakan kostum yang berlengan panjang.
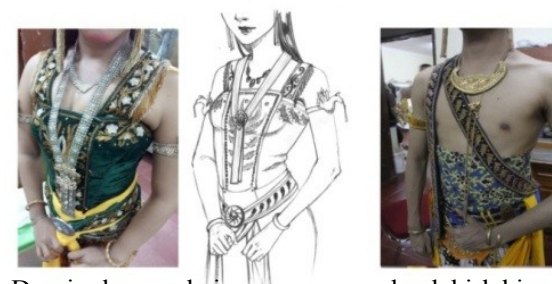

Gambar 7. Desain dasar pakaian perempuan dan laki-laki.

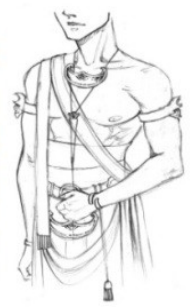

\section{3) Warna}

Warna yang digunakan dalam perancangan karakter ini juga mengacu kepada warna wayang orang dan wayang purwa. Seperti emas, merah, hijau, biru, dan hitam. Warna atribut biasanya banyak dihiasi dengan warna emas.

4) Desain Karakter

Setelah melakukan pengamatan pada karakter wayang purwa maupun wayang wong, menunju-kan bahwa adanya sifat yang sangat menonjol diantara yang baik maupun yang jahat. Sebelum mendesain kartu, tentunya harus dilakukan studi karakterisasi untuk setiap tokoh di dalam ilustrasi tarot wayang ini.

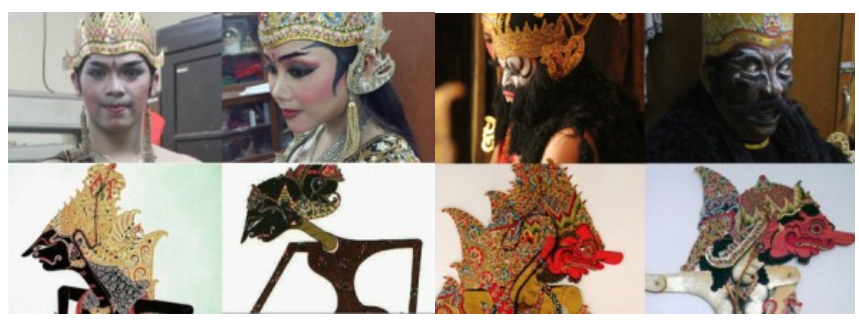

Gambar 8. Karakter Protagonis (Kiri) dan Karakter Antagonis (Kanan).

\section{Ilustrasi}

Dalam pembuatan tarot, gaya gambar apapun dapat diterima oleh pembaca tarot, asalkan dapat menunjukan visi dari penciptanya. Kalimat di atas sudah didasari oleh wawancara yang penulis lakukan dengan Barbara Moore.

\section{E. Tipografi}

Pemilihan font pada Tarot ini hanya satu, yaitu menggunakan serif. Hal ini dikarenakan font hanya digunakan sebagai judul dari kartu. Font serif berjudul Optimus Princeps digunakan karena terlihat lebih formal dan elegan.

\section{ABCDEFGHIJKLMNOPORSTUVWXYZ ABCDEFGHIJKLMNOPORSTU 1234567890}

\section{F. Layout}

Di dalam perancangan ini, kartu Tarot yang nantinya akan dicetak, harus memiliki layout yang rapi dan konsisten. Sehingga akan dibutuhkan tatanan Trim, Bleed dan Margin, agar hasil cetak terlihat sama dan tidak meleset dari hasil akhir.

\section{G. Ilustrasi Belakang Kartu}

Desain dari belakang kartu ini dibuat dengan vector. Media ini dipilih karena depan kartu sudah terlihat penuh dengan banyak warna. Namun setelah beberapa diskusi dan interview, banyak yg memilih belakang kartu yang lebih detail dan menggunakan ilustrasi.

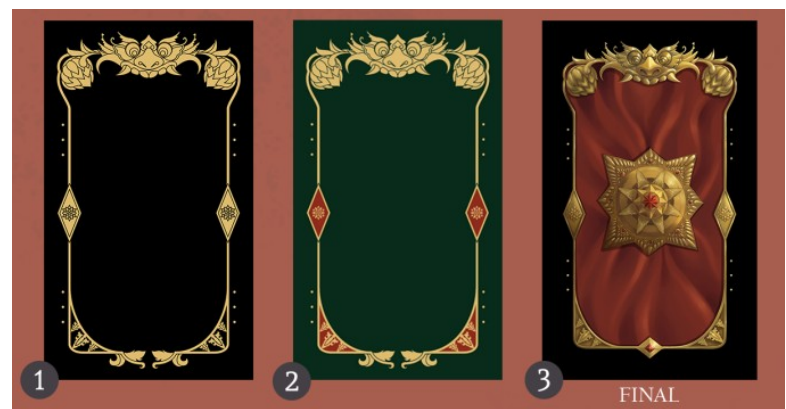

Gambar 9. Awal desain (kiri) sedikit pewanaan (tengah) dan desain final (kanan).

\section{H. Proses Desain}

1) Pemilihan Karakter

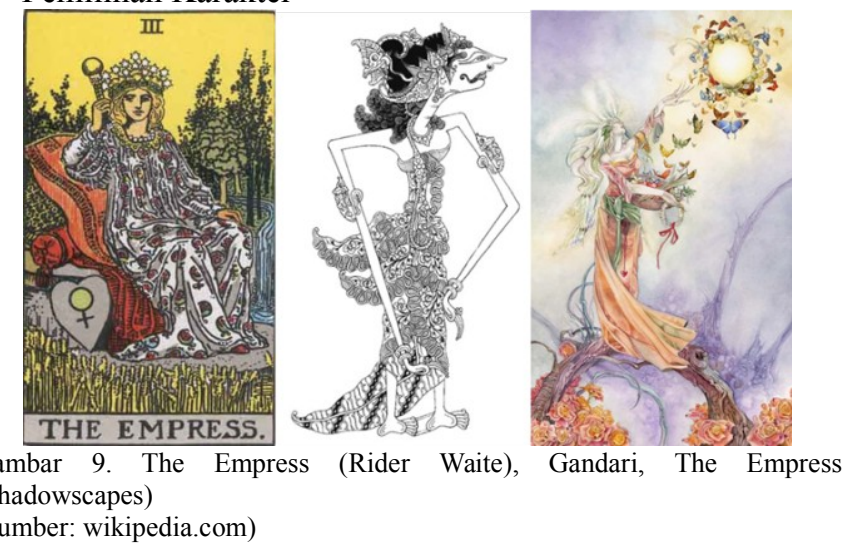

Dewi Gandari adalah sosok yang dipilih penulis untuk menjadi perwakilan kartu ini. Di dalam cerita Perwayangan, Gandari memang adalah sosok seorang wanita yang arogan dan sombong. Ia sangat menginginkan kedudukannya sebagai Ratu di Hastina. Tetapi itu tidak terjadi karena suaminya Destarata, anak pertama dari Prabu Wicitrasena tidak memiliki pengelihatan alias buta dan karena itulah ia tidak bisa menjadi Raja. Lalu berdoalah ia kepada dewata dan berharap dikaruniai anak banyak yang nanti bakal dapat menjadi raja. Doanya terkabul dengan lahirnya ke-101 anak Kurawa.

2) Pemilihan Simbol 


\author{
Nomor $\quad:$ III \\ Elemen : :Tanah \\ Planet/Zodiak : Venus \\ Inti Kartu : Kelimpahan dan Kreasi \\ Kata Kunci : Kehidupan, Cinta, Kesuburan, Kreatifitas, \\ Memelihara, Perduli, Proteksi, Kerja Keras, Panen, Kelahiran, \\ Kemakmuran.
}

Yang pertama adalah Gandari sendiri. Seorang ibu, yang sangat berkaitan dengan feminitas dan perempuan itu sendiri. Lalu kehamilan 101 Kurawa dari Gandari yang melambangkan kesuburan. Jika venus dilambangkan sebagai tanda astrologi dari wanita, maka laut adalah simbolisme dari wanita dan gunung sebagai laki-laki. Lalu mengambil simbolisme dalam warna batik, yaitu warna merah yang melambangkan selatan dan kesuburan untuk diaplikasikan [7].

3) Proses Sketsa

Proses sketsa adalah awal dari penciptaan sebuah ilustrasi. Pada proses ini, penulis dapat mencurahkan segala ide yang sudah ada di pikiran ke dalam kertas sebelum dieksekusi lebih lanjut.

Gambar 10. Sketsa the empress.
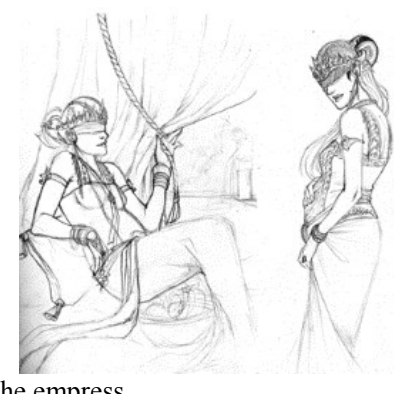

4) Proses Perwarnaan

Setelah melalui proses sketsa, jika dirasa sketsa tersebut telah cocok untuk di proses lebih lanjut, yaitu memberikan warna dasar kepada ilustrasi. Hal ini dilakukan agar warna yang diinginkan tidak jauh dari perkiraan. Penulis juga memisahkan 3 partisi ke dalam foreground, middleground, dan back-ground. Agar jika terjadi kesalahan, maka penulis dapat memperbaikinya tanpa menyentuh layer lain.

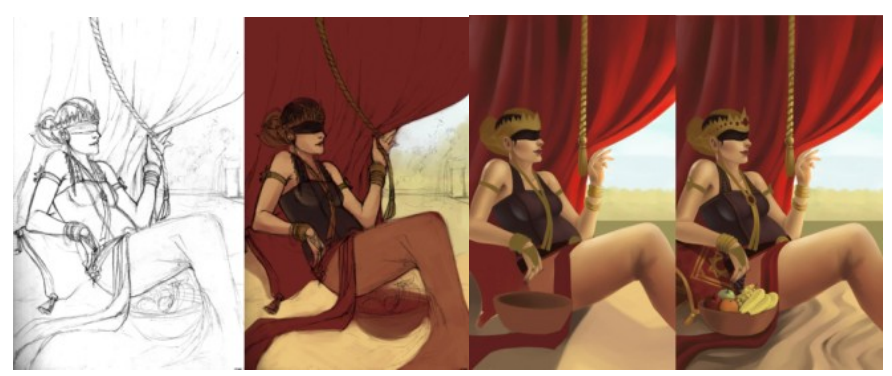

Gambar 11. Dari sketsa, ke base-color, dan proses rendering (kiri ke kanan).

5) Proses Finishing

Proses terakhir dalam ilustrasi adalah finishing dan retouching. Setelah itu, digabung-kan ilustrasi tersebut dengan desain border yang telah dibuat menyesuaikan jenis kartu.

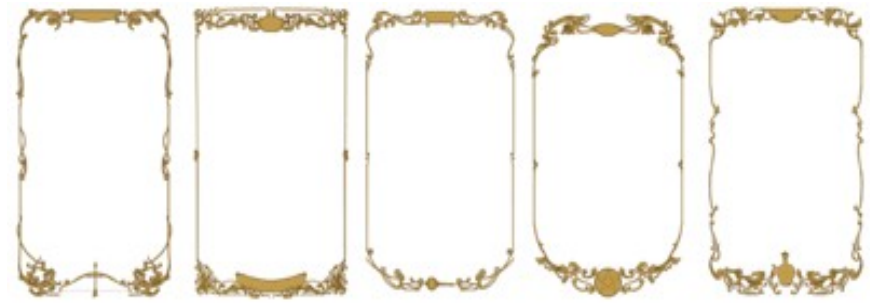

Gambar 12. Border Kartu untu Arkana Mayor, Arkana Minor (Air, Tanah, Api dan Angin).

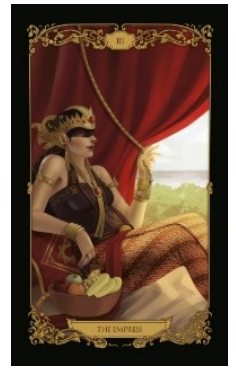

Gambar 13. Hasil akhir the empress.

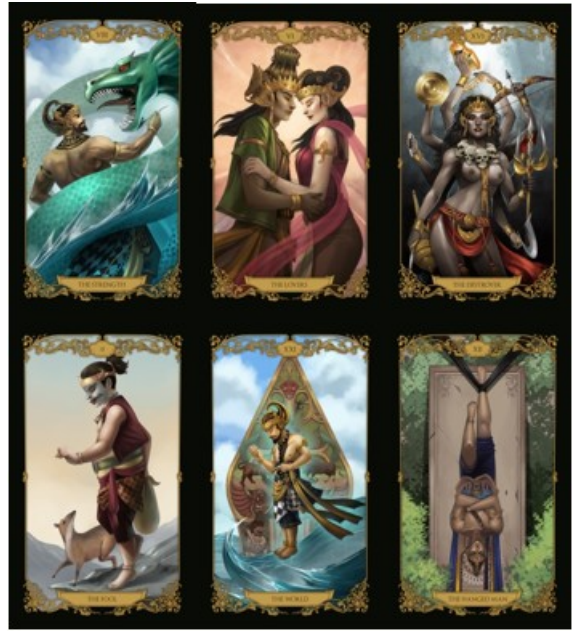

Gambar 14. Beberapa hasil akhir kartu arkana mayor.

\section{KESIMPULAN}

Perancangan Kartu Tarot Astadewa ini merupakan media yang digunakan untuk melestarikan kebudayaan Wayang Jawa. Di dalamnya terdapat banyak simbolisme-simbolisme Perwayangan yang mungkin tidak banyak diketahui oleh banyak orang. Kesimpulan dari perancangan ini meliputi masih belum ada yang menciptakan Tarot Wayang berceritakan kisah Mahabharata. Yang meliputi arketipe, kostum, ornament, dekorasi dan background. Tarot ini juga diharapkan menjadi penerus Tarot Wayang Ibu Ani yang sudah tidak lagi di produksi.

Saran yang diberikan untuk Tarot Astadewa ini adalah masih dibutuhkannya buku panduan bersanding dengan Tarot Astadewa ini sehingga lebih memudahkan pembaca Tarot untuk mendalami dan mempelajari simbolisme dalam kartu dek ini. Logonya juga masih dapat dikembangkan lagi dan perbaikan kualitas setiap kartunya sehingga tidak terlihat berbeda dengan satu sama lain. 
[1] L. Rimba and Audifax, Psikologi tarot. Yogjakarta: Pinus, 2008.

[2] E. Gray, The complete guide to the tarot. New York: Batam Books, 1970.

[3] T. Sentosa, Mahabarata. Jakarta: PLUZ+, 2009.

[4] H. A. Fachri, Tarot past, future, \& life. Jakarta: Gagasmedia, 2012.

[5] A. Sekarningsih, Panduan tarot wayang. Jakarta: PT. Grasindo,
2002 .

B. Moore, Shadowscapes companion. USA: Llewellyn Worldwide, 2010.

[7] F. Kerlogue, Batik: design, style, and history. United Kingdom: Thames and Hudson, 2004. 